\title{
Assessment of sewer flooding model based on ensemble quantitative precipitation forecast
}

\author{
Cheng-Shang Lee a,b ${ }^{a}$ Hsin-Ya Ho ${ }^{a}$, Kwan Tun Lee ${ }^{a, c, *}$, Yu-Chi Wang ${ }^{a}$, Wen-Dar Guo a , Delia Yen-Chu Chen ${ }^{\text {a }}$, \\ Ling-Feng Hsiao ${ }^{a}$, Cheng-Hsin Chen ${ }^{a}$, Chou-Chun Chiang ${ }^{a}$, Ming-Jen Yang ${ }^{\mathrm{a}, \mathrm{d}}$, Hung-Chi Kuo ${ }^{\mathrm{a}, \mathrm{b}}$ \\ ${ }^{a}$ Taiwan Typhoon and Flood Research Institute, National Applied Research Laboratories, Taipei 10093, Taiwan \\ ${ }^{\mathrm{b}}$ Department of Atmospheric Sciences, National Taiwan University, Taipei 10617, Taiwan \\ ${ }^{c}$ Department of River and Harbor Engineering, National Taiwan Ocean University, Keelung 20224, Taiwan \\ ${ }^{\mathrm{d}}$ Department of Atmospheric Sciences, National Central University, Chung-Li 32001, Taiwan
}

\section{A R T I C L E I N F O}

\section{Article history:}

Available online 29 October 2012

This manuscript was handled by Mustafa

Altinakar, Editor-in-Chief

\section{Keywords:}

Storm sewer

Inundation evaluation

Quantitative precipitation forecast

Metropolitan areas

\section{S U M M A R Y}

Short duration rainfall intensity in Taiwan has increased in recent years, which results in street runoff exceeding the design capacity of storm sewer systems and causing inundation in urban areas. If potential inundation areas could be forecasted in advance and warnings message disseminated in time, additional reaction time for local disaster mitigation units and residents should be able to reduce inundation damage. In general, meteorological-hydrological ensemble forecast systems require moderately long lead times. The time-consuming modeling process is usually less amenable to the needs of real-time flood warnings. Therefore, the main goal of this study is to establish an inundation evaluation system suitable for all metropolitan areas in Taiwan in conjunction with the quantitative precipitation forecast technology developed by the Taiwan Typhoon and Flood Research Institute, which can be used for inundation forecast $24 \mathrm{~h}$ before the arrival of typhoons.

In this study, information for the design capacity of storm sewer throughout Taiwan was collected. Two methods are proposed to evaluate the inundations: (a) evaluation based on the criterion of sewer capacity (CSC), and (b) evaluation based on the percentage of ensemble members (PEM). In addition, the probability of inundation is classified into four levels (high, medium, low, and no inundation). To verify the accuracy of the proposed system, Typhoon Megi and Typhoon Nanmadol were used as test cases. Four verification indices were adopted to evaluate the probability of inundation for metropolitan areas during typhoons. The inundation evaluation results basically match the observed data on flooding, which demonstrate that this flood evaluation system has an effective grasp on the probability of inundation for storm sewer systems.

(c) 2012 Elsevier B.V. All rights reserved.

\section{Introduction}

Taiwan is geographically located directly in the path of northwest Pacific typhoons. Previously determined statistics (19582010) show that an average of 29.2 typhoons form each year, 3.4 of which affect Taiwan, and $76 \%$ of the cases occur during the months of July to September. The swift socio-economic development in recent years has enlarged the area covered by urban growth. Urban storm sewer systems are often incapable of withstanding and satisfying the current and future demands of urban development. Therefore, when typhoons or torrential rains arrive,

* Corresponding author at: Department of River and Harbor Engineering, National Taiwan Ocean University, Keelung 20224, Taiwan. Tel.: +886 2 24622192x6121; fax: +886224634122.

E-mail address: ktlee@ntou.edu.tw (K.T. Lee). severe inundations occur if the incoming rainfall exceeds the design rainfall intensity of the storm sewer system. For example, the torrential rain accompanying Typhoon Kalmaegi in 2008 caused widespread damage in the coastal townships of Pingtung County (the maximum accumulated rainfall was $706 \mathrm{~mm}$ within 42 h). In 2009, Typhoon Morakot brought record-breaking precipitation, the maximum total accumulated rainfall was $3060 \mathrm{~mm}$ within the whole affecting period -6 days, the maximum observed daily rainfall for 8 August and 9 August were both more than $1000 \mathrm{~mm}$, which caused widespread inundation damage from continuous rainfall. The main inundation area encompassed three cities and nine counties in Taiwan. In 2011, Typhoon Nanmadol (the maximum accumulated rainfall was $1117 \mathrm{~mm}$ within $84 \mathrm{~h}$ ) reached southern Taiwan and caused heavy inundation in the regions surrounding Pingtung and Kaohsiung. In the same year, Typhoon Nalgae also caused disastrous damage in Yilan, although it 
did not make landfall to Taiwan and the typhoon center was far from the terrain. The circulation of Typhoon Nalgae interacted with the northeasterly monsoon flow, and the convergence flow enhanced and locked by the topographical lifting. It also produced continuous heavy rainfall (the maximum accumulated rainfall was $1621 \mathrm{~mm}$ within $72 \mathrm{~h}$ ).

Taiwan encounters increasingly damaging typhoons in recent years (Emanuel, 2005; Liu et al., 2009). However, the protection offered by existing flood prevention engineering is limited. To reduce the overall damage from typhoons, torrential rain, and floods, appropriate non-structure damage mitigation methods must be adopted in addition to currently available engineering solutions. There are many non-structure approaches, such as: (1) establishing flood prone area restrictions to avoid high-density developments in potential flood areas; (2) developing flood forecast or early warning systems so that residents living in potential flood areas can evacuate in time to reduce flood damage and loss; (3) emphasizing knowledge and education of the potential threat of floods to reduce residents and mitigate losses; (4) establishing flood insurance to share or allocate risks; and (5) conserving soil and water in the watershed to reduce surface runoff during storms. One of the most effective methods among the non-structure solutions is the disaster warning and response measures (Reed, 1984; Yu and Chen, 2005). By controlling and understanding typhoon and torrential rain movements beforehand, timely inundation warnings and initiation of preventive measures in potential disaster areas should significantly minimize the losses from disasters.

The precipitation forecasting plays a crucial role in developing a flood warning system. Hydrological forecasting models and meteorological forecasting models are two approaches to forecasting rainfall (Yu et al., 2004). The hydrological forecasting models (for example, Burlando et al., 1993; Luk et al., 2001) are focused on short duration precipitation forecasts $(1-3 \mathrm{~h})$, which are suitable for real-time flood forecast operations. The meteorological forecasting models (for example, Docine et al., 1999) emphasize predicting precipitation potential and belong to long-duration precipitation forecasts ( $24 \mathrm{~h}$ or more). Hydrologists usually employ statistical methods to conduct short-duration precipitation forecasts. Probabilistic models and stochastic models are frequently applied. The Markov-chain model is the most representative probabilistic model, which uses statistical probability to describe the hereditary effect for before- and after-periods during precipitation (Klatt and Schultz, 1983; Zevin, 1986). However, statistical models generally require numerous samples that satisfy the assumption of historic precipitation events sharing the same statistical characteristics with the precipitation event being forecast. Since the short lead-time is considered insufficient for pre-disaster warning, this has driven the development of meteorological forecasts in recent years.

In long-duration precipitation forecasts, quantitative precipitation forecasts (QPF) using numerical weather models are usually applied. The Fifth Generation Penn State/NCAR Mesoscale Model (MM5) developed by Pennsylvania State University (PSU) and the National Center for Atmospheric Research (NCAR) is widely used for precipitation forecasts (Dudhia, 1993; Grell et al., 1994). Recently, the next generation of mesoscale Weather Research and Forecasting Model (WRF) developed by NCAR and supporting organizations has gradually replaced the MM5 model (Skamarock et al., 2005). The WRF model provides various atmospheric physical parameter methods for use in atmospheric research and practical organizations. Since different assumptions are involved in each physical parameter method, they can also be used in various weather types, geographical regions, and specific conditions.

Regarding ensemble forecasts, a real-time MM5 forecasting system was established in 1996 by Cliff Mass and his research group at the University of Washington in Seattle. The main region of fore- cast was the northwestern US (Colle et al., 2000). The data from the forecasts can be used not only for academic research but also for providing operational reference to the local National Weather Service (NWS). The University of Washington further developed a real-time ensemble forecast system which can manage multiple sets of simulation simultaneously to improve forecasting capability of the mesoscale ensemble forecast method (Grimit and Mass, 2002). Yang and Ching (2005) used the MM5 model to simulate Typhoon Toraji in 2001. Results from the ensemble modeling experiments revealed that selecting proper physical parameters can improve the modeling of typhoon paths and precipitation distribution. Jankov et al. (2005) conducted QPF verifications for case studies using alternative physical parameter method combinations in the WRF model. Chien et al. (2006) designed 12 sets of sensitivity tests to evaluate the precipitation forecast capability of the WRF model. They also determined the optimal combination of the physical parameters for precipitation simulations in Taiwan and the South China region during the plum rains.

Numerous experts in recent years have actively pursued establishing a flood early warning system to reduce damage from disasters. Cunge et al. (1980), Chen et al. (2005) and Chen et al. (2006) developed warning systems that integrated precipitation, watershed runoff, one-dimensional flood routing, and two-dimensional inundation modeling. These kinds of systems combined hydraulic models and geographic information system techniques and have effectively improved the precision of inundation forecasts. Tanguy et al. (2005) developed the French Flood Forecasting Service, SCHAPI, for assessing the evolution of floods and for daily publication of the French flood vigilance chart. Some studies investigated the use of the Flash Flood Guidance (FFG) method and improved the accuracy of flash flood forecasts (Sperfslage et al., 2004; Georgakakos, 2006; Norbiato et al., 2008). More recently, by incorporating the weather forecasts from the German Weather Service (DWD) and the European Centre, Thielen et al. (2009) and Bartholmes et al. (2009) developed the European Flood Alert System (EFAS) to provide early warning information for floods in Europe with a lead time up to 10 days. Versini et al. (2010) proposed a distributed hydrological model for a road inundation warning system and investigated flash flood prone areas in the Gard region of south of France.

To reduce frequent losses due to urban inundation in Taiwan, the authorities are urgently developing an integrated meteorological-hydrological forecast models for inundation evaluation. However, general watershed hydrological modeling is unable to simulate runoff for flooding warning for entire Taiwan because of the complexity in model input and the lengthy computing time of the model. Therefore, developing a fast inundation evaluation system based on statistical or conceptual models is considered required. Based on the results of ensemble QPF designed by the Taiwan Typhoon and Flood Research Institute (TTFRI), the main task of this study is to develop a system that can effectively evaluate inundation and provide warning message for townships throughout Taiwan. Two methods for evaluating storm sewer inundations are proposed: (a) evaluation based on the criteria of sewer capacity (CSC), and (b) evaluation based on the percentage of ensemble members (PEM). The main concept of the CSC method is to multiply the design rainfall intensity of the storm sewer by different factors to classify four levels of inundation probability (high, medium, low, and no inundation). The PEM method involves using the percentage of ensemble members whose forecast precipitation exceeds the storm sewer design criterion. To verify the accuracy of the proposed inundation system, the observed inundation data are compared with the evaluation results by using four evaluation indices for Typhoon Megi and Typhoon Nanmadol. Inundation evaluations based on the CSC and PEM methods were also analyzed detailed. 


\section{Methodology}

This study combines the results from QPF and the design rainfall intensity of the storm sewer to construct an inundation evaluation system for the metropolitan areas of Taiwan. The proposed system is capable of providing risk evaluation for inundation in urban areas $24 \mathrm{~h}$ before the arrival of typhoons.

\subsection{Typhoon Quantitative Precipitation Forecast Ensemble Experiment (TYQPFE)}

The complex topography of Taiwan makes QPF especially important. This study used the precipitation forecast results of the Typhoon Quantitative Precipitation Forecast Ensemble Experiment (TYQPFE) that has been conducted by the TTFRI since 2010. The TYQPFE combined the research abilities and efforts from the academic institutes in Taiwan (National Taiwan University, National Central University, National Taiwan Normal University, and Chinese Culture University) and the practical operation units (Central Weather Bureau) with the computational resources of the National Center for High-Performance Computing (NCHC) and the disaster prevention experience of the National Science and Technology Center for Disaster Reduction (NCDR). This is the first attempt to design a high-resolution numerical ensemble model in Taiwan. The goal of the TYQPFE experiment is to develop and test the QPF to provide inundation information for disaster prevention.

Numerical weather forecast uses all types of observation data gathered worldwide (such as satellites, radar, atmospheric sounding, and ground observations) for numerical simulations. The numerical simulations are performed on a super computer, which can provide precipitation forecasts of the next 3 days within $2-3 \mathrm{~h}$ after receiving the observation data. Considering the limitation of numerical models, we performed ensemble forecasting techniques to reduce the uncertainty of model simulations. Ensemble forecasting applied various models and initial conditions for precipitation forecast. The model used for 2010 case was the WRF model, and the mesoscale models MM5 from NCAR and Cloud-Resolving Storm Simulator (CReSS) from Nagoya University were added in 2011. In addition to multi-modal choices, perturbations in the ensemble model also employ data assimilation and various cumulus parameterizations to provide the spread of the ensemble forecasting. The average or weighted combination of all of the members was used as the final precipitation forecast. When typhoons were affecting Taiwan, this experiment generated four runs a day in a $5 \mathrm{~km}$ resolution. The ensemble statistical method and probabilistic forecast concept were used to analyze the typhoon path and precipitation distribution. The 2010 ensemble data used in this study contains 15 sets of WRF model results. In 2011, because of the additional MM5 and CReSS modeling results, there are a total of 20 ensemble members providing the precipitation forecasting for inundation warnings.

\subsection{Flood evaluation model based on TYQPFE}

Generally, flood forecasts are focused on river stage, dam breaches or overbank, and lowland inundations. To obtain precise forecasts regarding these situations, hydrologists can use 1D or 2D flood forecast models to conduct numerical routing of the watershed being studied and to forecast river stage or the extent and depth of inundation. However, in performing real-time forecasts, numerical instability may result from solving water continuity and momentum equations due to inadequate precipitation data input, local topography, and the setting of model initial conditions. In addition, 2D physically-based inundation model computations are time-consuming and less suitable for the needs of emergency responses. Considering these restrictions, the timeliness of warnings can be greatly enhanced if inundation warnings can be provided without using physically-based models. Generally, inundation causes fall into one of the following categories: (1) dam overflows caused by high river stage; (2) inundation caused by dam breaches; (3) insufficient drainage caused by strong precipitation; or (4) sea water encroachment caused by storm surges or tsunamis. Among these, the first and the third items are directly linked with precipitation. The other two are more closely related to tidal levels, dam structure, and other factors. There are also human factors or mechanical failures that cause inundations, such as open sluice gates or malfunctioning pumps. Because this study aims at developing a fast inundation evaluation system using TYQPFE results, only situations with insufficient drainage capacity caused by strong precipitation were considered. Other factors and human-caused inundations were not considered when developing this system because of the high level of uncertainty.

This system is mainly concerned with urban inundations caused by insufficient drainage capacity of storm sewers under a specified protection level. Since urbanization causes increasing the runoff peak due to the shortened time of concentration, existing storm sewers are often unable to accommodate the bursts of torrential rain, which causes manhole overflow and urban inundation. Therefore, in this study we used design rainfall intensity of the storm sewer to compare with the QPF to determine the probability of inundation.

\subsubsection{Algorithm for evaluating inundation probability}

The storm sewer design criteria of 314 townships (urban area) throughout Taiwan were collected from the Construction and Planning Agency of the Ministry of the Interior (Taiwan). Two factors are related to the design criteria. The first one is the rainfall duration which is set to equal to the time of concentration of the sewer drainage system. The second one is the design return period which is based on the considerations of cost and safety. In general, the design return period for a sewer system is about $2-5$ years according to the development condition of the area, and the time of concentration of the system ranges from $30 \mathrm{~min}$ to $2 \mathrm{~h}$. To match the time scale of TYQPFE, we used $1-\mathrm{h}$ and 2 -h precipitation intensities for inundation evaluation.

Based on the sewer design criteria from the Construction and Planning Agency, we found that in some townships, the cumulative rainfall depth calculated from the 2-h design rainfall intensity is less than that calculated from the 1-h design rainfall intensity, which is obviously unreasonable and requires for further correction. Since the 2-h design rainfall depth is nearly 1.5 times the 1$\mathrm{h}$ design rainfall depth for most of the townships in Taiwan, we assumed the 2-h design rainfall depth equal to 1.5 times the 1 -h design rainfall depth for the correction of aforementioned unreasonable situation.

The main function of a storm sewer system, which is one of the basic infrastructures of modern cities, is to drain street runoff in time to avoid flooding damage. In fact, the maintenance and management of storm sewers have often been neglected in Taiwan. Sludge from construction sites flows into conduits; sand quarry operators illegally discharge wastewater from sand washing; civilians dump garbage; and pipelines crisscross underground. All of these human or natural factors significantly influence the function of storm sewers. Consequently, storm sewer systems usually fall below their original design drainage capacity. Considering that storm sewer systems are incapable to operate at $100 \%$ capacity, this study proposes two methods for evaluating the inundation probability, which are described below:

(1) Evaluation based on the criteria of sewer capacity (CSC) 
In this study, the original sewer design criterion is multiplied by various factors, and then they are used to compare with the QPF; consequently, a group of inundation probability forecast can be obtained. Four inundation probabilities are proposed as follows:

(a) No inundation: QPF is less than $55 \%$ of the design criterion.

(b) Low probability: QPF is between 55\% and $85 \%$ of the design criterion.

(c) Medium probability: QPF is between $85 \%$ and $115 \%$ of the design criterion.

(d) High probability: QPF is greater than $115 \%$ of the design criterion.

Afterwards, the 1- and 2-h precipitation intensities are linked using the following equation as a guideline for evaluating inundation (Guo et al., 2011).

$E_{i, t}=\max \left(E_{i, t}^{d=1}, E_{i, t}^{d=2}\right)$

in which

$E_{i, t}^{d=1}=\left(\begin{array}{ccc}\text { High } & \text { if } & R_{i, t}^{\text {Prediction }}>1.15 R_{i, d=1}^{\text {Design }} \\ \text { Medium } & \text { if } & 0.85 R_{i, d=1}^{\text {Design }}<R_{i, t}^{\text {Prediction }}<1.15 R_{i, d=1}^{\text {Design }} \\ \text { Low } & \text { if } & 0.55 R_{i, d=1}^{\text {Design }}<R_{i, t}^{\text {Prediction }}<0.85 R_{i, d=1}^{\text {Design }} \\ \text { None } & \text { if } & R_{i, t}^{\text {Prediction }}<0.55 R_{i, d=1}^{\text {Design }}\end{array}\right.$

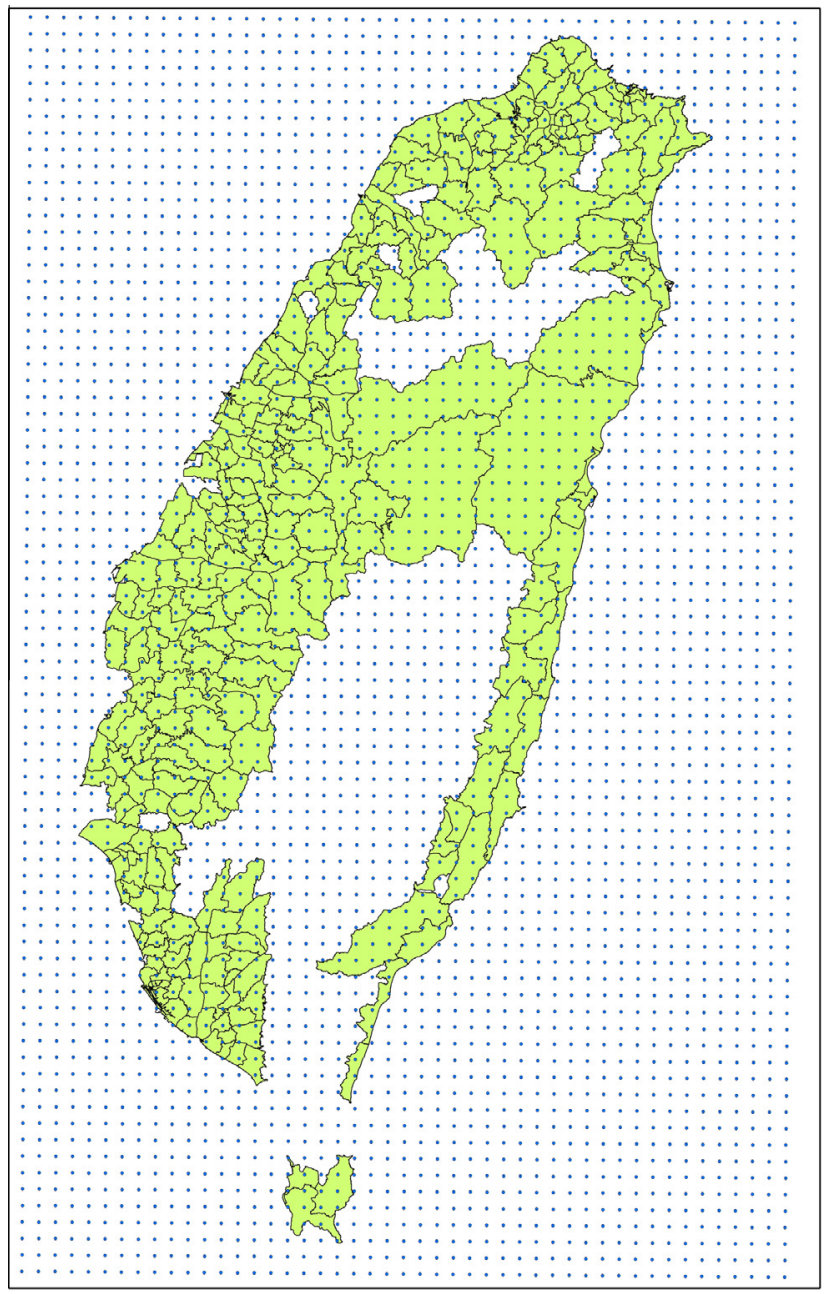

(a)

$$
E_{i, t}^{d=2}=\left(\begin{array}{ccc}
\text { High } & \text { if } & 0.5\left(R_{i, t-1}^{\text {Prediction }}+R_{i, t}^{\text {Prediction }}\right)>1.15 R_{i, d=2}^{\text {Design }} \\
\text { Medium } & \text { if } & 0.85 R_{i, d=2}^{\text {Design }}<0.5\left(R_{i, t-1}^{\text {Prediction }}+R_{i, t}^{\text {Prediction }}\right)<1.15 R_{i, d=2}^{\text {Design }} \\
\text { Low } & \text { if } & 0.55 R_{i, d=2}^{\text {Design }}<0.5\left(R_{i, t-1}^{\text {Prediction }}+R_{i, t}^{\text {Prediction }}\right)<0.85 R_{i, d=2}^{\text {Design }} \\
\text { None } & \text { if } & 0.5\left(R_{i, t-1}^{\text {Prediction }}+R_{i, t}^{\text {Prediction }}\right)<0.55 R_{i, d=2}^{\text {Design }}
\end{array}\right.
$$

where $i$ represents a township, $t$ is the time currently evaluated, $d$ is the duration, $R_{i, t}^{\text {Prediction }}$ is the QPF (hourly precipitation) in township $i$ at time $t, R_{i, d=1}^{\text {Design }}$ is the 1-h design precipitation intensity in township $i, R_{i, d=2}^{D e s i g n}$ is the 2-h design precipitation intensity in township $i, E_{i, t}^{d=1}$ is the inundation probability for 1 -h precipitation at time $t$ in township $i$, and $E_{i, t}^{d=2}$ represents the inundation probability for 2-h precipitation at time $t$ in township $i$. The maximal inundation probability from the evaluation results of $E_{i, t}^{d=2}$ and $E_{i, t}^{d=1}$ is used to evaluate the inundation probability at time $t$.

(2) Evaluation based on the percentage of ensemble members (PEM).

Because the TYQPFE implies the concept of probabilistic forecasting, we attempted to determine the inundation probability according to the percentage of members exceeding the sewer design criteria. In other words, if more members predict the precipitation exceeding the design criteria of the storm sewer, the township has a higher inundation probability. The inundation probability is defined as:

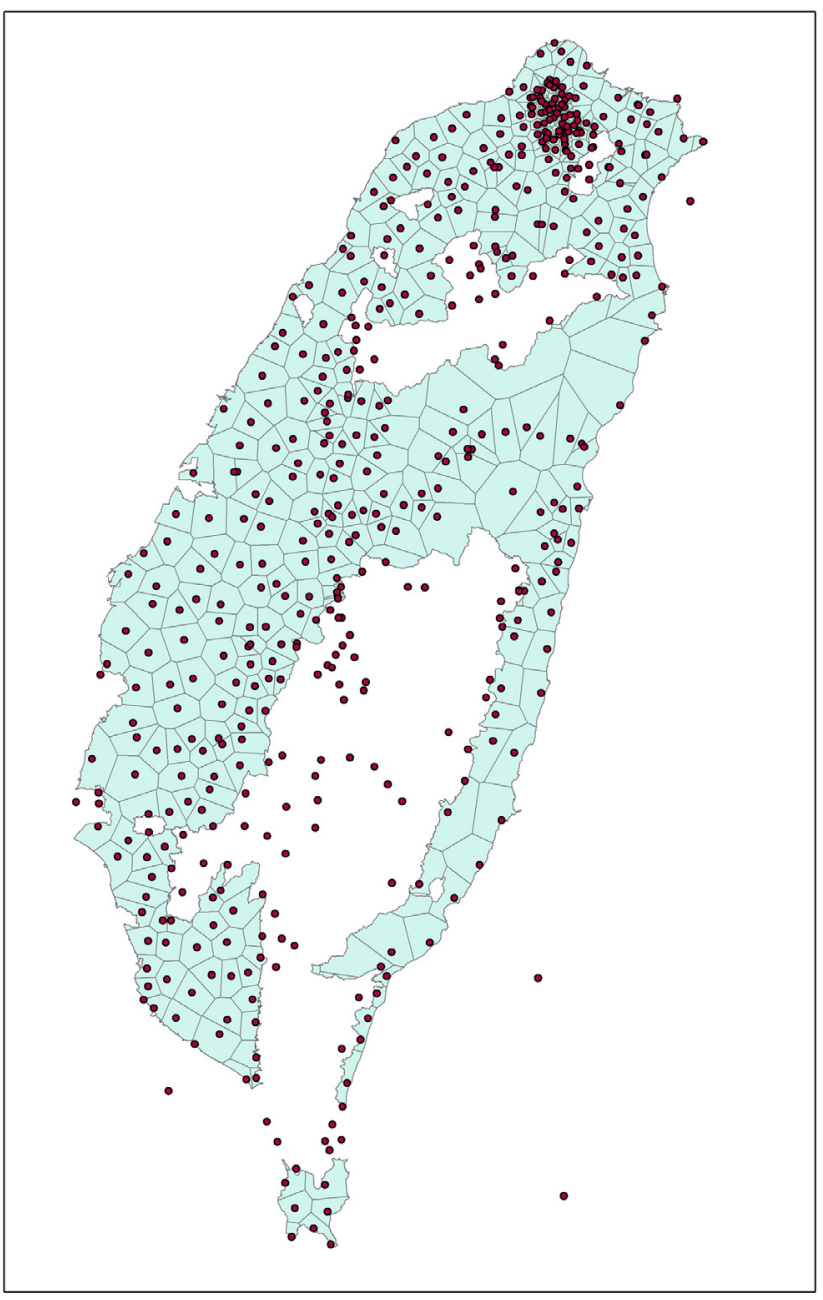

(b)

Fig. 1. (a) Overlapping quantitative precipitation output points and townships in Taiwan and (b) precipitation points shown in Thiessen control area diagram. 
$E_{i, t}=\left(\frac{M}{T M}\right)_{i, t}^{\text {Prediction }}$

in which

(a) high inundation probability: $E_{i, t}>50 \%$;

(b) medium inundation probability: $25 \%<E_{i, t}<50 \%$;

(c) low inundation probability: $0 \%<E_{i, t}<25 \%$;

(d) no inundation: $E_{i, t}=0$. where $E_{i, t}$ is the inundation probability; $M$ is the number of ensemble forecast members when the forecast precipitation is greater than the storm sewer design criterion, and TM is the total number of members.

\section{Model applications}

The proposed inundation evaluation model was applied to the metropolitan areas in Taiwan. The Typhoon Quantitative Precipita-

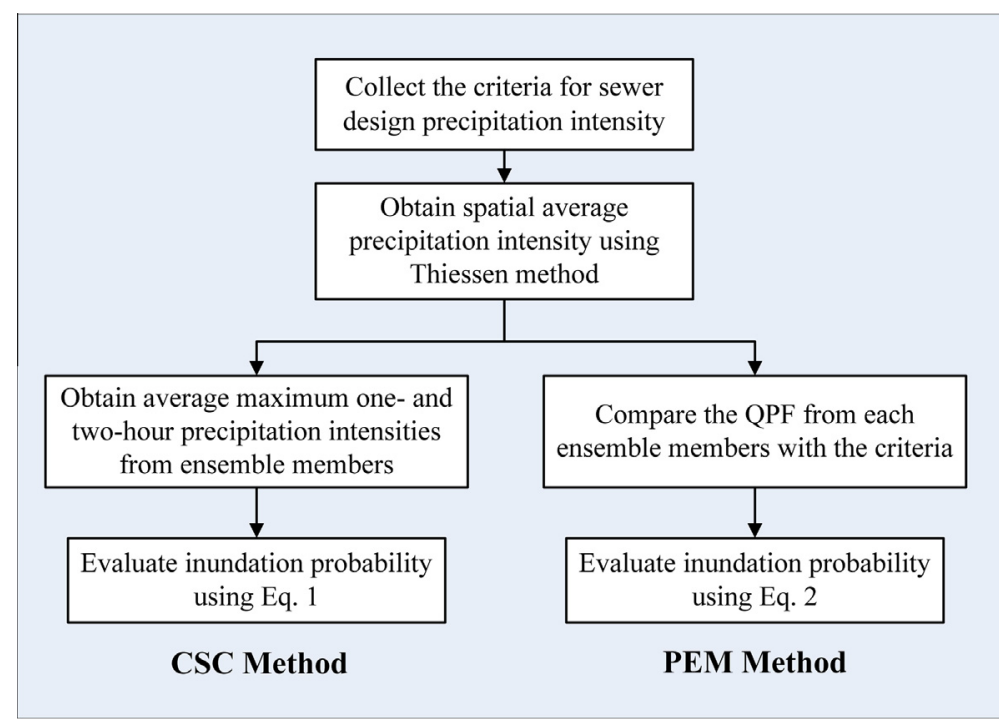

Fig. 2. Data processing of the inundation evaluation model.

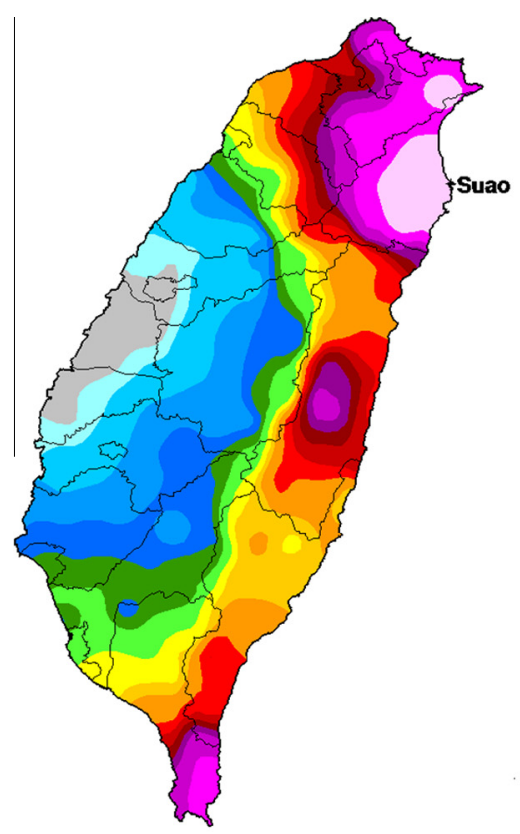

(a)

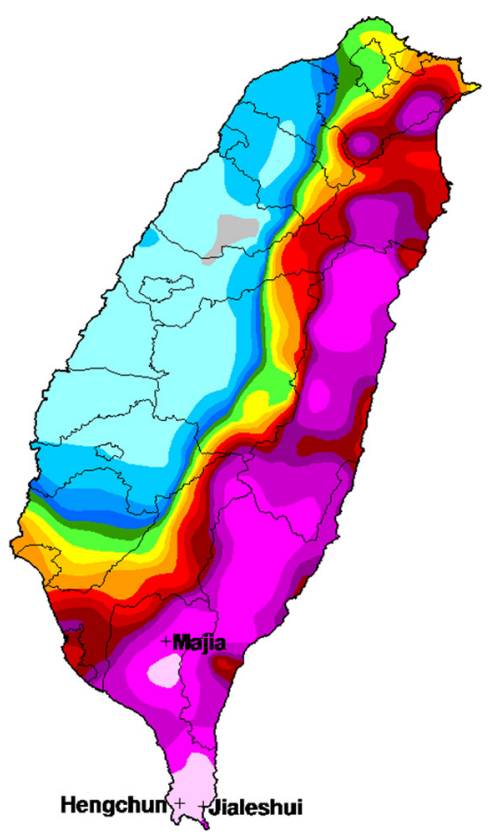

(b)

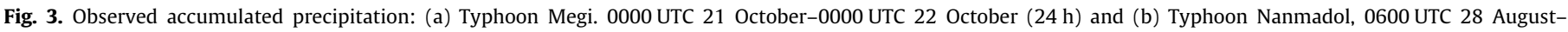
0600 UTC 29 August (24 h). 


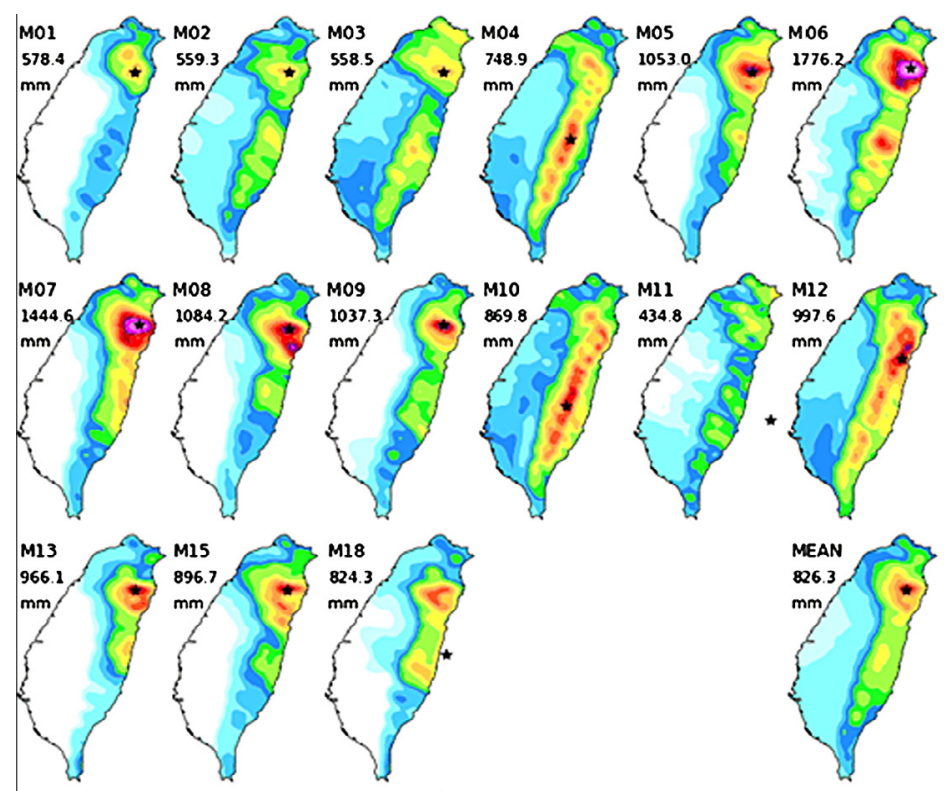

(a)
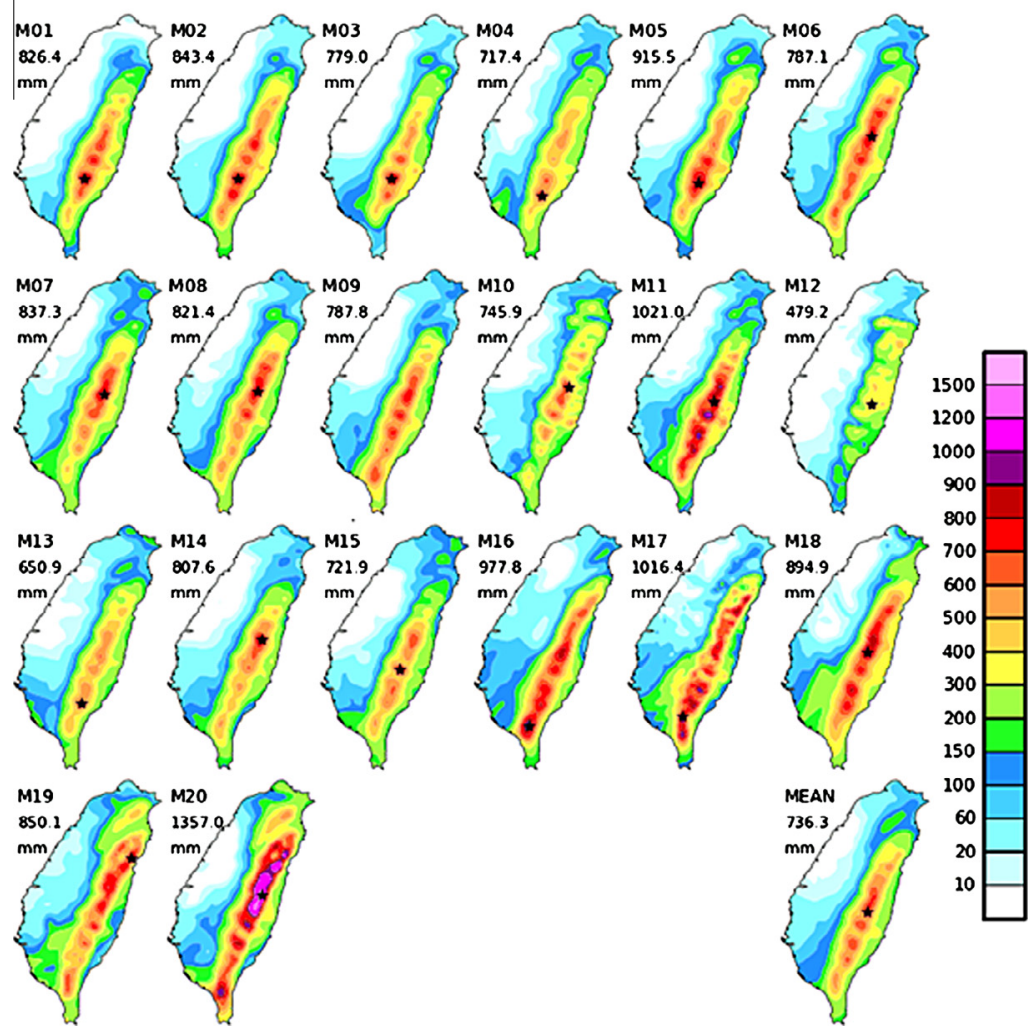

(b)

Fig. 4. Ensemble members and mean accumulated precipitation: (a) Typhoon Megi. 0000 UTC 21 October-0000 UTC 22 October (24 h) and (b) Typhoon Nanmadol, 0600 UTC 28 August-0600 UTC 29 August (24 h).

tion Forecast Ensemble Experiment has been conducted by the Taiwan Typhoon and Flood Research Institute (TTFRI) since 2010, so only two typhoon events are available for this analysis.

\subsection{QPF data processing}

Since the coordinate systems of the TYQPFE platform and the township coverage are different, coordinate transformation was performed to link with these two systems. To compare the QPF results with observed precipitation data, the QPF was spatially interpolated to the locations of the rain-gauging stations and used for further inundation evaluation (as shown in Fig. 1a). For a large township, the spatial-averaged precipitation was calculated by using the Thiessen polygon method (as shown in Fig. 1b). The spatial-average precipitation series of each township were then used in the two methods for inundation prediction. 
The processes of integrating QPF are different in performing the two inundation-probability-evaluation methods. In the CSC Method, ensemble precipitation cannot be directly averaged to obtain the forecast hourly precipitation because of the variation of the initial conditions used in the numerical simulation of the members. If the forecast precipitations are averaged, the precipitation peak would then be diminished. Therefore, in performing the CSC method, the maximum 1- and 2-h precipitation depths were calculated by using the 24-h QPF series from different members, and then the maximum values were averaged and substituted into Eq. (1) for inundation estimation. Nevertheless, the predicted 24-h QPF series were directly adopted to check the exceedence probability of flooding in the PEM method (as shown in Eq. (2)). Consequently, the merit of the PEM method is to preserve the ensemble probability of the 24-h QPF series from all the members. The data processing of the inundation evaluation system is shown in Fig. 2.

\subsection{Typhoon Megi}

The lifecycle of Typhoon Megi was from 13 October to 23 October 2010. The land warning for Taiwan was issued from 0930 UTC 21 October to 1530 UTC 23 October, for a total of $54 \mathrm{~h}$. The maximal wind velocity of Typhoon Megi is $48 \mathrm{~m} \mathrm{~s}^{-1}$ measured by the Central Weather Bureau (CWB) of Taiwan. Previous studies have indicated that typhoon cases accompanying with a northeasterly monsoon easily caused heavy rainfall in the northern and eastern part of Taiwan. Lee et al. (2007) analyzed the accompanying pre- cipitation from such typhoon cases. Aside from that caused by the accompanied effect between the typhoon and the northeasterly monsoon, a large part of the precipitation was caused either by the circulation of the typhoon itself or by the terrain lifting effect. For example, Typhoon Zeb in 1998 caused heavy precipitation in northern Taiwan. In addition to the precipitation provided by the mid-latitude trough, part of the precipitation was caused by the circulation of the typhoon, with the terrain playing a key role (Chou et al., 2001). Another type of case occurs when the center of the typhoon is still far away from northern Taiwan (approximately $400-500 \mathrm{~km}$ or more in distance), the outer circulation and large-scale flow field may combine to cause heavy rainfall (Lee et al., 2007).

The accompanied effect from Typhoon Megi brought extreme precipitation to northern and northeastern Taiwan. Analyzing the accumulated precipitation data shows that heavy precipitation occurred in the Yilan area (Fig. 3a). The maximal 72-h accumulated rainfall measured at the Suao observation station was $1168 \mathrm{~mm}$. Fig. 4a shows the accumulated precipitation for mean results and individual members in ensemble model forecasts. The forecast results show that all members have forecasted the occurrence of strong precipitation in the Yilan area. However, the locations of strong precipitation were found to differ by a few kilometers. Affected by the combination of outer circulation and northeasterly monsoon, Typhoon Megi poured extremely heavy rain on the Yilan area. During the typhoon period, the hourly rainfall reached $180 \mathrm{~mm}$ and has broken the record in Taiwan. The maximal accumulated precipitation over $24 \mathrm{~h}$ exceeded $1000 \mathrm{~mm}$, causing se-

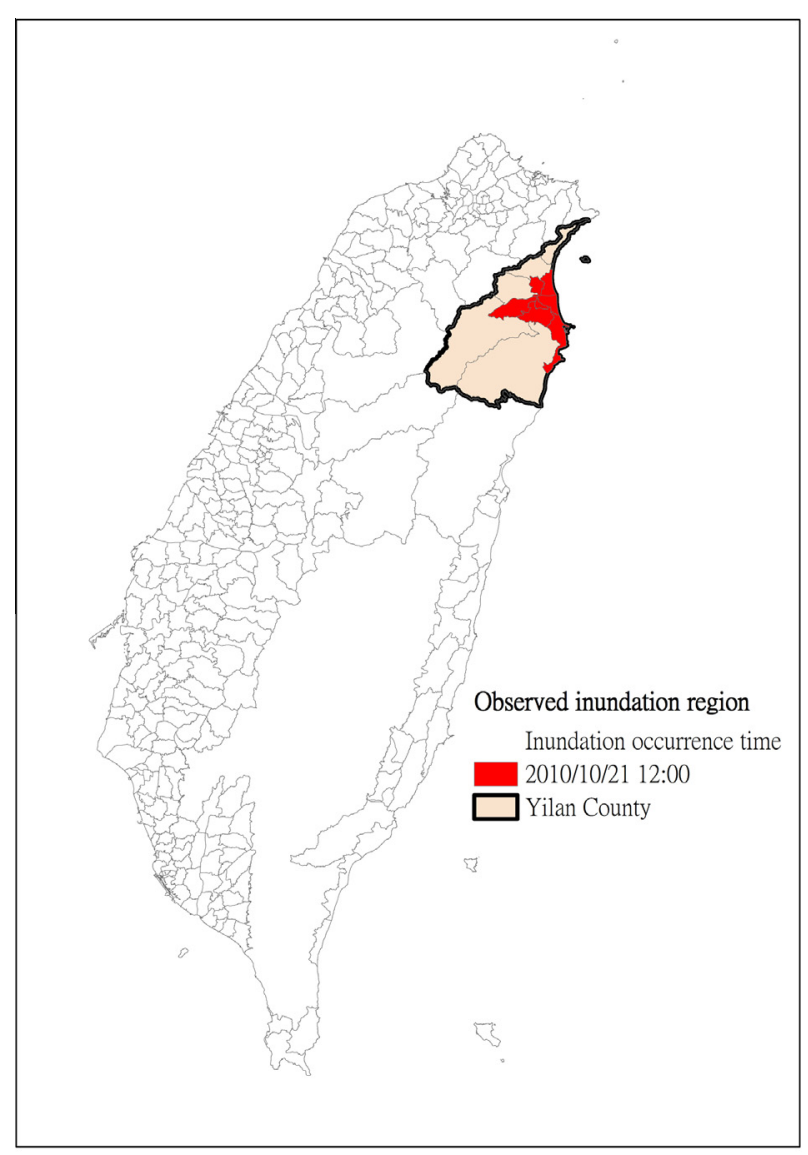

(a)

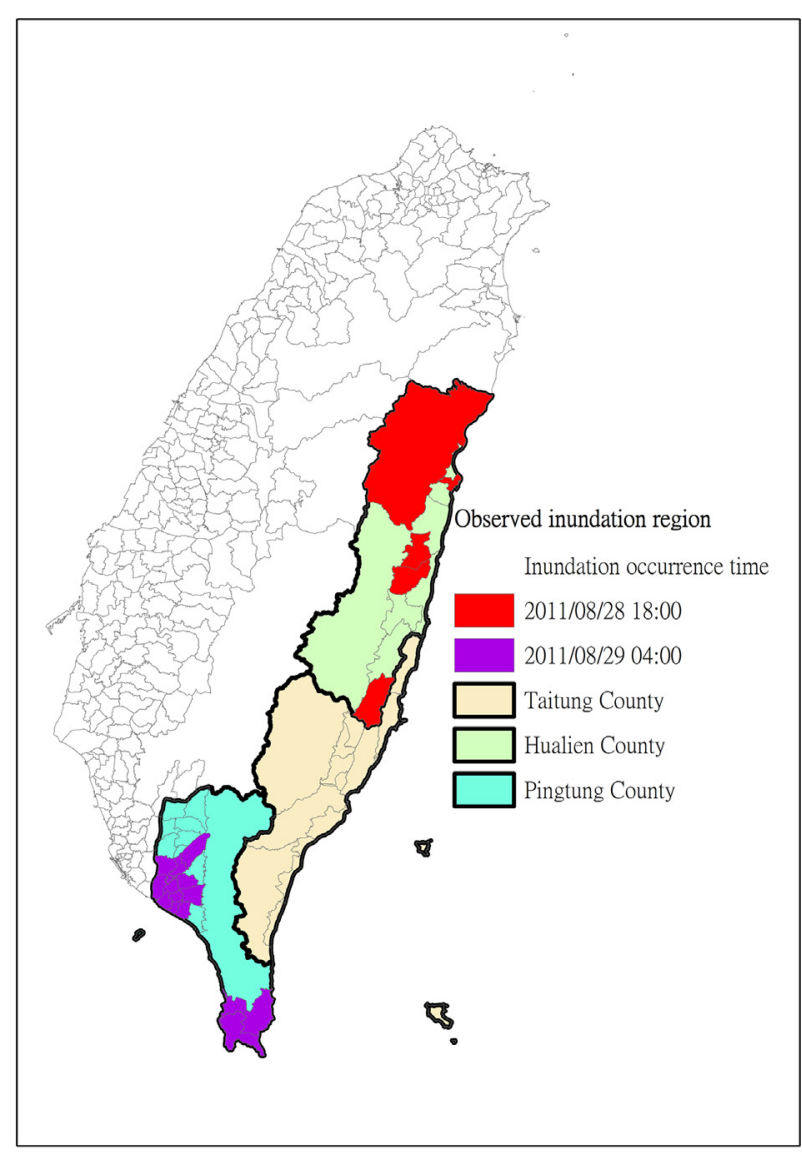

(b)

Fig. 5. Map of observed inundation: (a) Typhoon Megi and (b) Typhoon Nanmadol. 
vere inundation damage in many townships in Yilan as shown in Fig. 5a. In fact, the maximum storm sewer capacity for 1-h precipitation intensity is only $78.9 \mathrm{~mm} / \mathrm{h}$ for the main metropolitan of Taiwan currently.

\subsection{Typhoon Nanmadol}

The lifecycle of Typhoon Nanmadol was from 22 August 2011 to 31 August 2011. The land warning was issued from 1230 UTC 27 August 2011 to 0030 UTC 31 August 2011, for a total of $84 \mathrm{~h}$. The maximal intensity of this typhoon is defined as a super typhoon $\left(53 \mathrm{~m} \mathrm{~s}^{-1}\right)$ by the CWB of Taiwan. Analyzing the accumulated precipitation of Typhoon Nanmadol shows that heavy precipitation was mainly concentrated on the eastern Taiwan and Pingtung areas (Fig. 3b). The largest accumulated precipitation was observed in the Jialeshui observation station at $1123 \mathrm{~mm}$. The Majia station in the mountainous area of Pingtung also recorded $755 \mathrm{~mm}$ of accumulated precipitation. Fig. $4 \mathrm{~b}$ shows the accumulated precipitation for mean results and individual members in ensemble model forecasts. The forecast results show that numerical models overestimated the precipitation in the eastern Taiwan during Typhoon Nanmadol. However, the strong precipitation in the south of Pingtung was not effectively forecast. Consequently, there is still room for improvement in the numerical model forecasts for such local precipitation caused by mesoscale systems.

The inundations during Typhoon Nanmadol were caused by the total amount and the heavy intensity of precipitation. According to the records from the Hengchun observation station during Ty- phoon Nanmadol, the largest daily precipitation was $469 \mathrm{~mm}$, and the largest 2-day precipitation was $775 \mathrm{~mm}$. Both exceeded the 200-years return period precipitation and the design capacity of local drainage systems. The 4-day continuous precipitation with accumulated depth exceeding $1000 \mathrm{~mm}$ caused severe inundation damage as shown in Fig. 5b. The damage was most severe in Pingtung County. The 3-day accumulated precipitation in Hengchun peninsula exceeded $900 \mathrm{~mm}$ which caused a wide range of inundation in many places.

\section{Results and discussion}

\subsection{Verification method}

This study used the dichotomous (yes/no) forecasts verification method of the World Weather Research Programme/Working Group on Numerical Experimentation (WWRP/WGNE) Joint Working Group on Forecast Verification Research. A contingency table was used as the basis for determining whether a forecast should be "yes" or "no" according to a set threshold value. For precipitation verification, the threshold value is first selected. In this study, $50,130,200$, and $350 \mathrm{~mm}$ were chosen for accumulated-precipitation threshold values of $24 \mathrm{~h}$ according to the experiences of CWB. Occurrences of both forecasts precipitation and observations for a station being below the threshold value were tallied as "correct rejections." Occurrences of the forecast precipitation for an observation station being lower than the threshold but the actual record

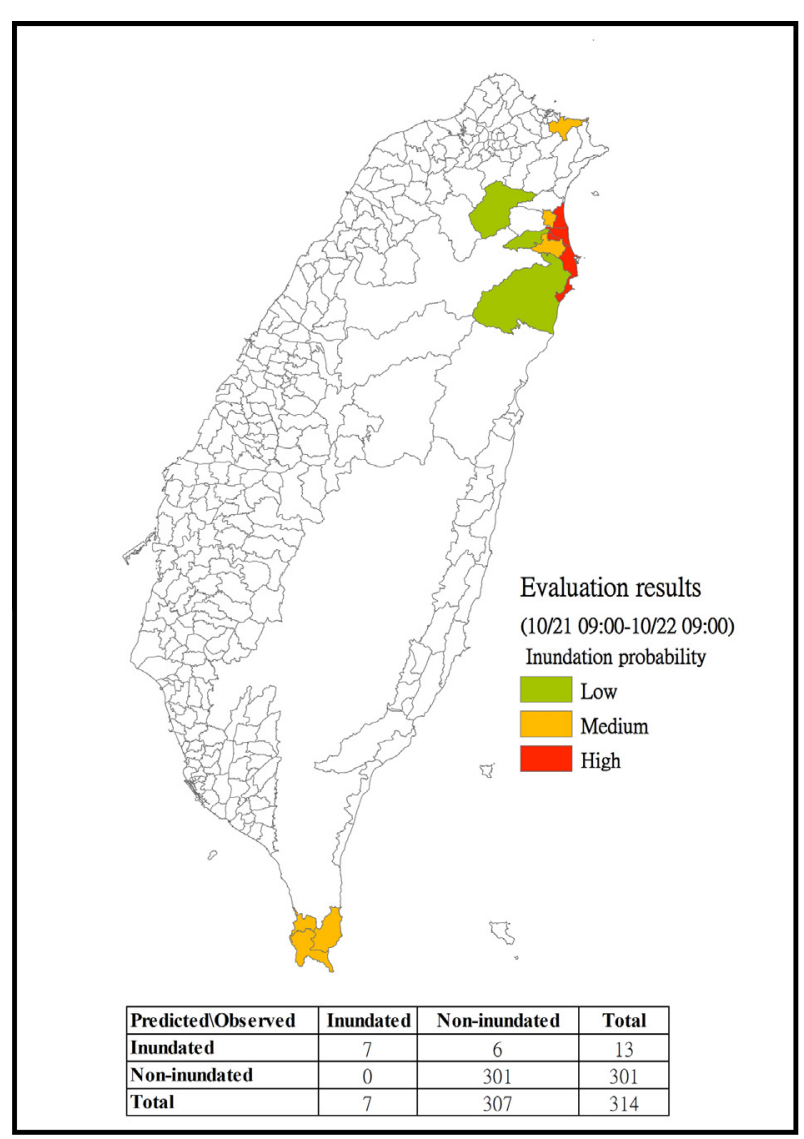

(a)

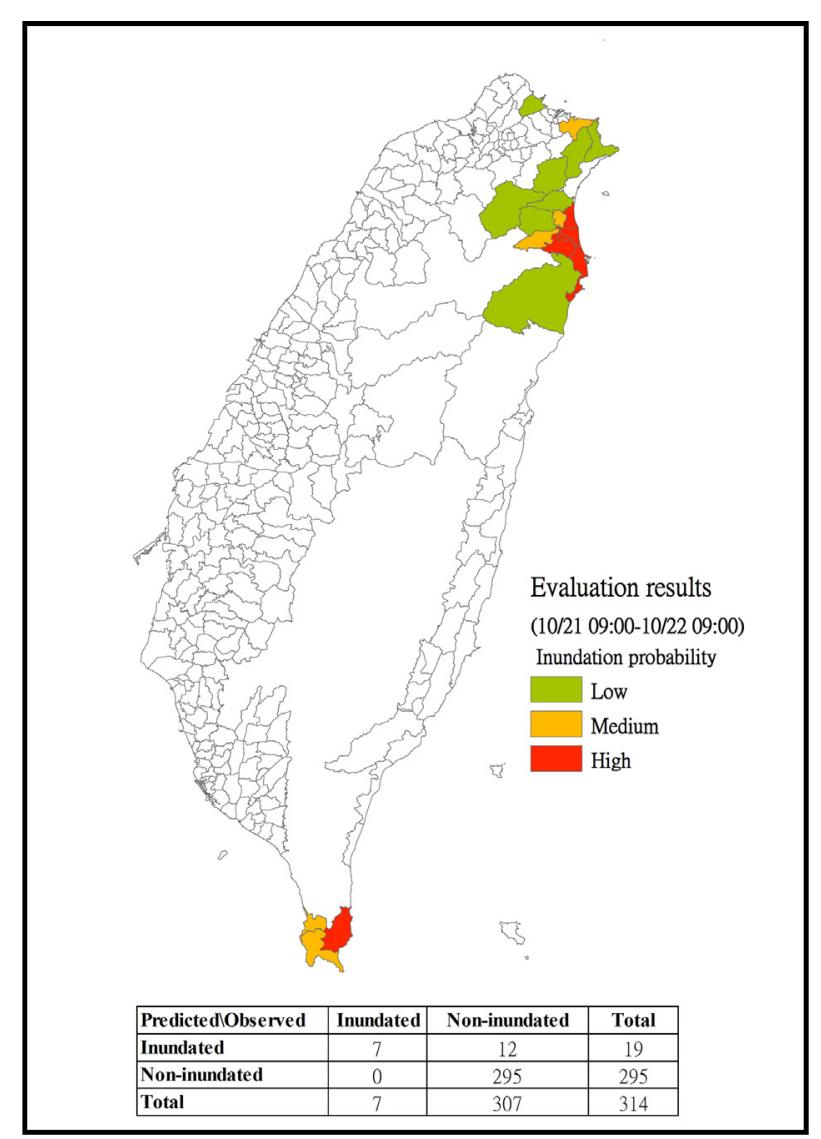

(b)

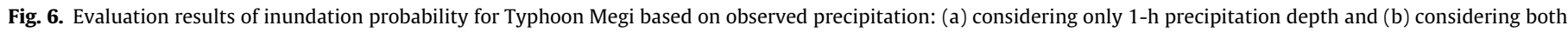
1- and 2-h precipitation depths. 


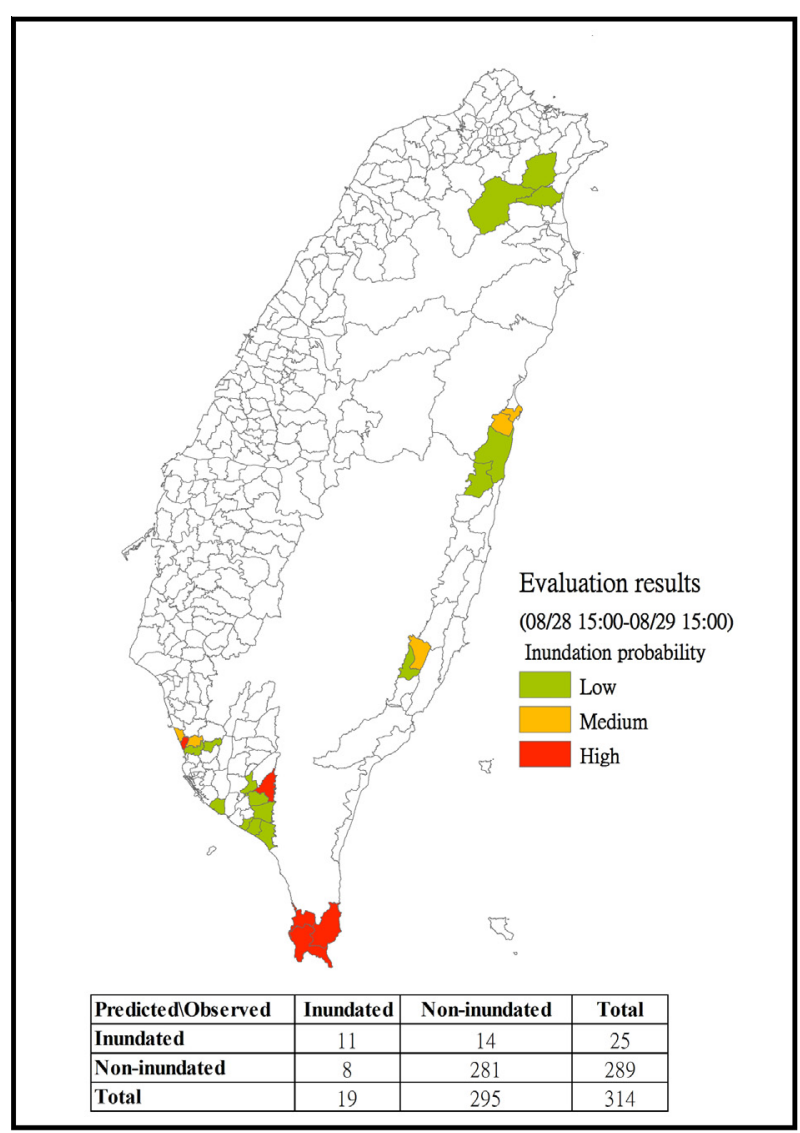

(a)

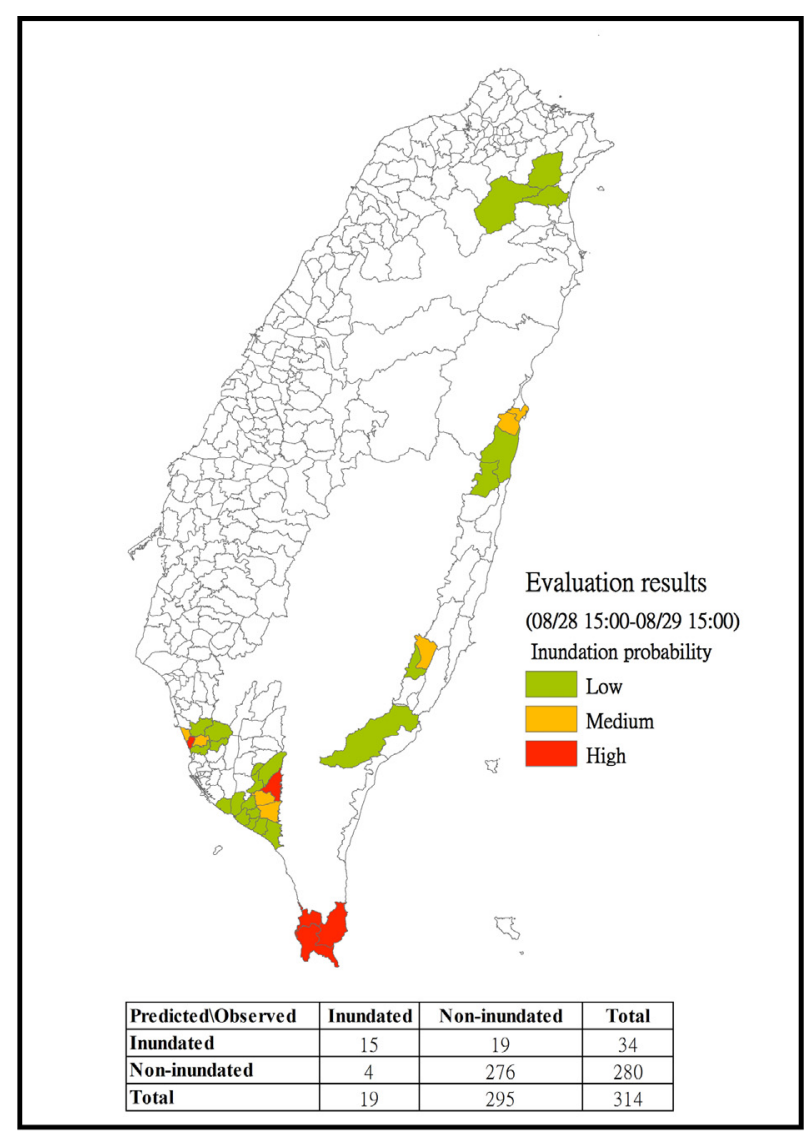

(b)

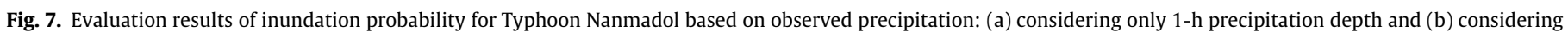
both 1- and 2-h precipitation depths.

Table 1

Verification results for Typhoon Megi.

\begin{tabular}{|c|c|c|c|c|}
\hline \multirow[t]{2}{*}{ Indices } & \multicolumn{2}{|c|}{$\begin{array}{l}\text { Using observed precipitation data } \\
\text { Precipitation duration }\end{array}$} & \multicolumn{2}{|c|}{$\begin{array}{l}\text { Using TYQPFE precipitation data } \\
\text { Evaluation method }\end{array}$} \\
\hline & Only 1 -h precipitation data & Both 1- and 2-h precipitation data & CSC & PEM \\
\hline BS & 1.857 & 2.714 & 3.286 & 4.714 \\
\hline POD & 1.000 & 1.000 & 0.857 & 0.857 \\
\hline FAR & 0.462 & 0.632 & 0.739 & 0.818 \\
\hline TS & 0.538 & 0.368 & 0.250 & 0.176 \\
\hline
\end{tabular}

Table 2

Verification results for Typhoon Nanmadol.

\begin{tabular}{|c|c|c|c|c|}
\hline \multirow[t]{2}{*}{ Indices } & \multicolumn{2}{|c|}{$\begin{array}{l}\text { Using observed precipitation data } \\
\text { Precipitation duration }\end{array}$} & \multicolumn{2}{|c|}{$\begin{array}{l}\text { Using TYQPFE precipitation data } \\
\text { Evaluation method }\end{array}$} \\
\hline & Only 1 -h precipitation data & Both 1- and 2-h precipitation data & CSC & PEM \\
\hline BS & 1.316 & 1.789 & 1.158 & 2.632 \\
\hline POD & 0.579 & 0.789 & 0.474 & 0.316 \\
\hline FAR & 0.560 & 0.559 & 0.591 & 0.880 \\
\hline TS & 0.333 & 0.395 & 0.281 & 0.095 \\
\hline
\end{tabular}

being above the threshold were tallied as "misses." Occurrences of the forecast precipitation for an observation station being higher than the threshold value but the actual precipitation being lower were tallied as "false alarms." Occurrences of both the forecast and actual precipitation of an observation station being higher than the threshold value were tallied as "hits." According to the contingency tables, four evaluation standards or indices can be calculated to verify precipitation forecasts:
(1) Bias Score (BS)

Bias $=\frac{\text { hits }+ \text { false alarms }}{\text { hits }+ \text { misses }}$

A BS value over 1 signifies "over-forecast," whereas a value under 1 signifies "under-forecast." This scoring system is used only to describe the relative relationship between forecasts and observa- 
Table 3

Ensemble forecast evaluation results for Typhoon Megi (model initiated at 1800 UTC 20 October 2010, verify period 0000 UTC 21 October-0000 UTC 22 October 2010).

\begin{tabular}{lllll}
\hline Threshold value & $50 \mathrm{~mm}$ & $130 \mathrm{~mm}$ & $200 \mathrm{~mm}$ & $350 \mathrm{~mm}$ \\
\hline BS & 1.59 & 1.25 & 1.21 & 1.37 \\
POD & 1.00 & 0.99 & 0.97 & 0.91 \\
FAR & 0.37 & 0.21 & 0.20 & 0.34 \\
TS & 0.63 & 0.78 & 0.78 & 0.62
\end{tabular}

Table 4

Ensemble forecast evaluation results for Typhoon Nanmadol (model initiated at 0000 UTC 28 August 2011, verify period 0600 UTC 28 August-0600 UTC 29 August 2011).

\begin{tabular}{lllll}
\hline Threshold vlaue & $50 \mathrm{~mm}$ & $130 \mathrm{~mm}$ & $200 \mathrm{~mm}$ & $350 \mathrm{~mm}$ \\
\hline BS & 1.52 & 1.63 & 1.65 & 1.40 \\
POD & 1.00 & 1.00 & 0.99 & 0.99 \\
FAR & 0.34 & 0.39 & 0.40 & 0.29 \\
TS & 0.66 & 0.61 & 0.60 & 0.70 \\
\hline
\end{tabular}

tions, and cannot be used to describe how close the forecast results are to the observations.

(2) Probability of Detection (POD)

POD $=\frac{\text { hits }}{\text { hits }+ \text { misses }}$

The POD describes the ratio of correct forecasts. This value considers only hits and ignores false alarms, and tends to have a high

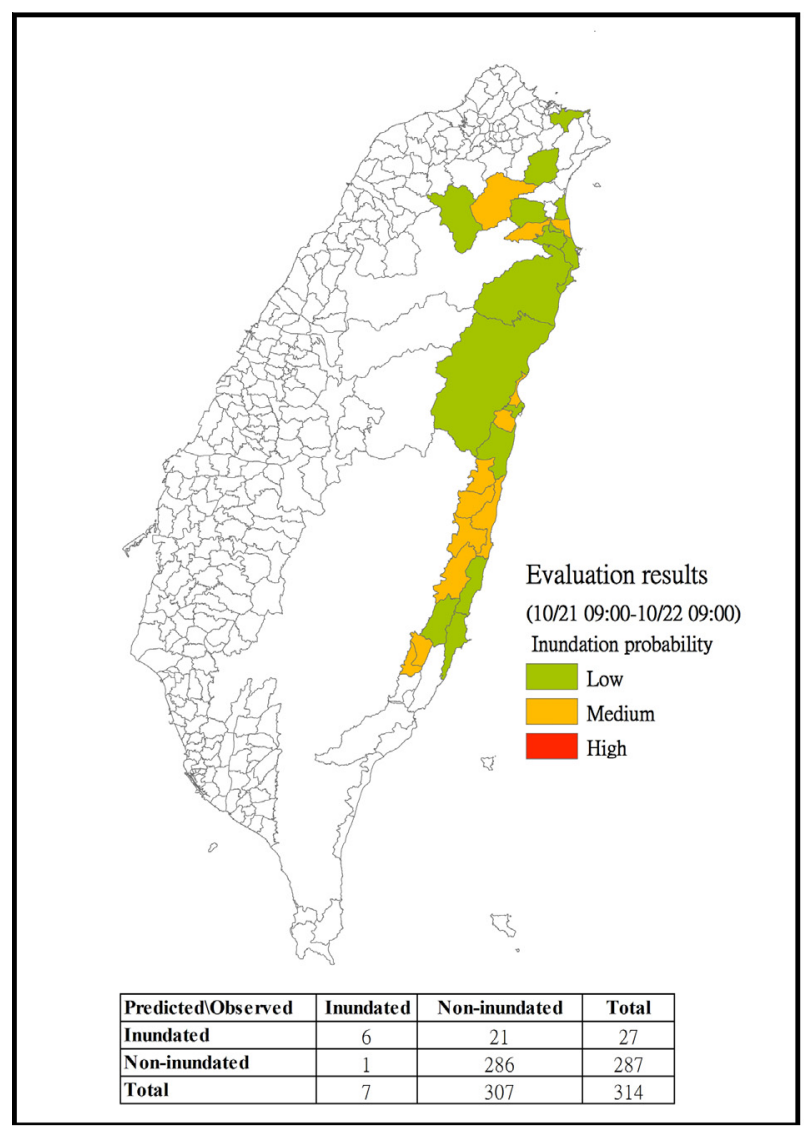

(a) value for forecasts of rare cases. The false alarm ratio should be considered when the POD is used.

(3) False Alarm Ratio (FAR)

$\mathrm{FAR}=\frac{\text { false alarms }}{\text { hits }+ \text { false alarms }}$

The FAR describes the ratio of false alarms.

(4) Threat Score (TS)

$\mathrm{TS}=\frac{\text { hits }}{\text { hits }+ \text { misses }+ \text { false alarms }}$

The TS is so called the critical success index (CSI). This score excludes the situation when both the forecast and actual precipitation are lower than threshold value; thus, it could be considered as the "correct percentage" of the forecast model. The TS value is 0 when there is no forecast capability.

By conducting the aforementioned analysis, the forecast results of ensemble precipitation forecasting could be interpreted according to different precipitation thresholds. Regarding inundation forecast verification, this study also used similar verification score calculation methods to determine if the forecast should be yes/no based on whether actual inundation is present.

\subsection{Inundation evaluation using observed precipitation}

To test the evaluation performance of the proposed system, we adopted precipitation records from rain-gauging stations to evalu-

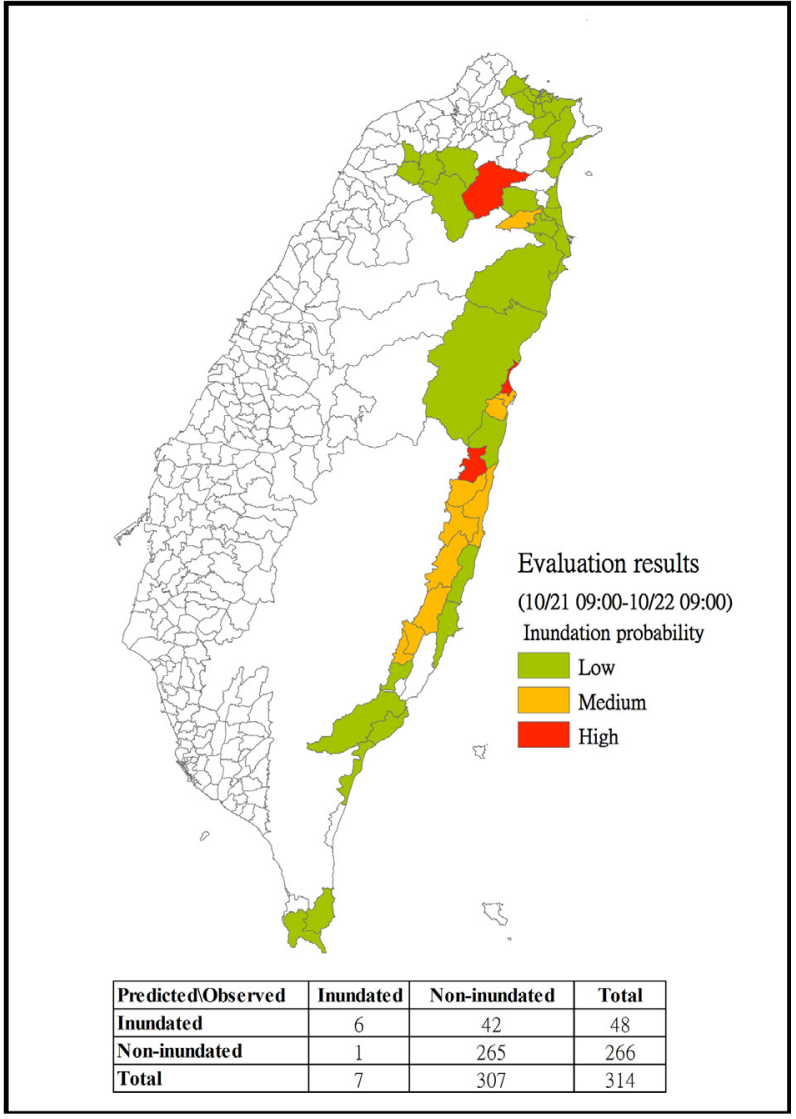

(b)

Fig. 8. Evaluation results of inundation probability for Typhoon Megi based on TYQPFE precipitation by (a) CSC method and (b) PEM method. 


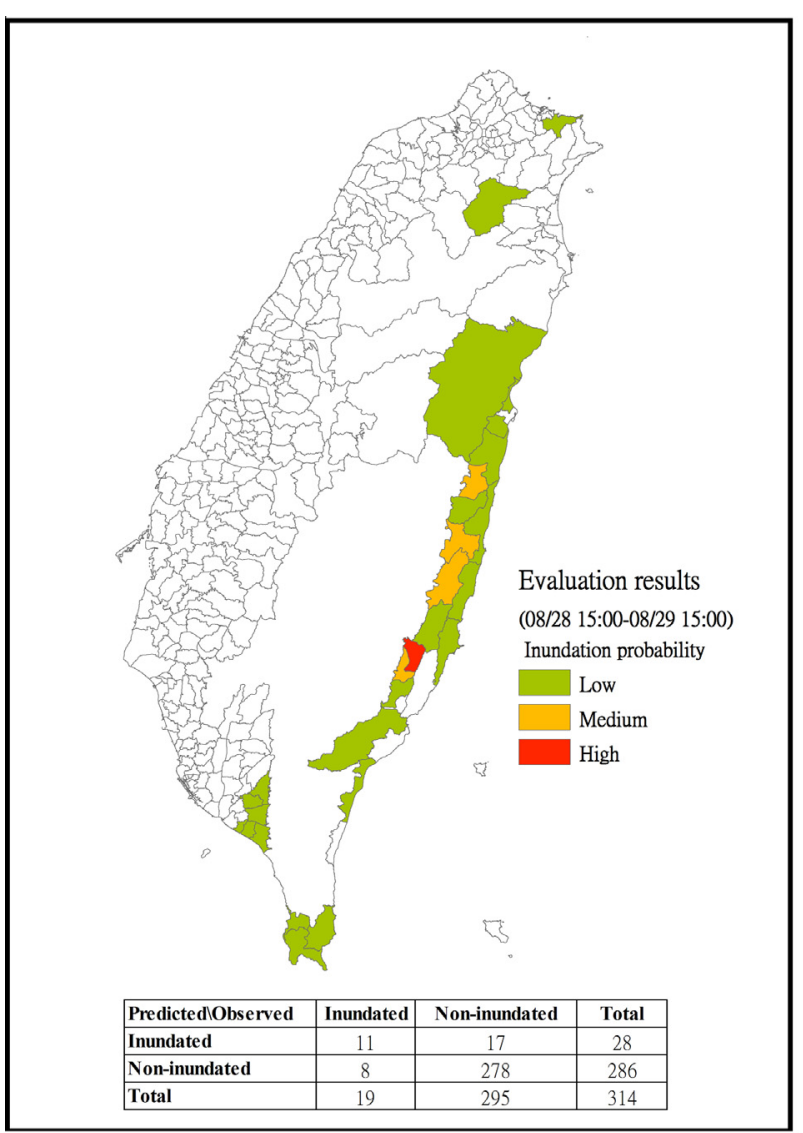

(a)

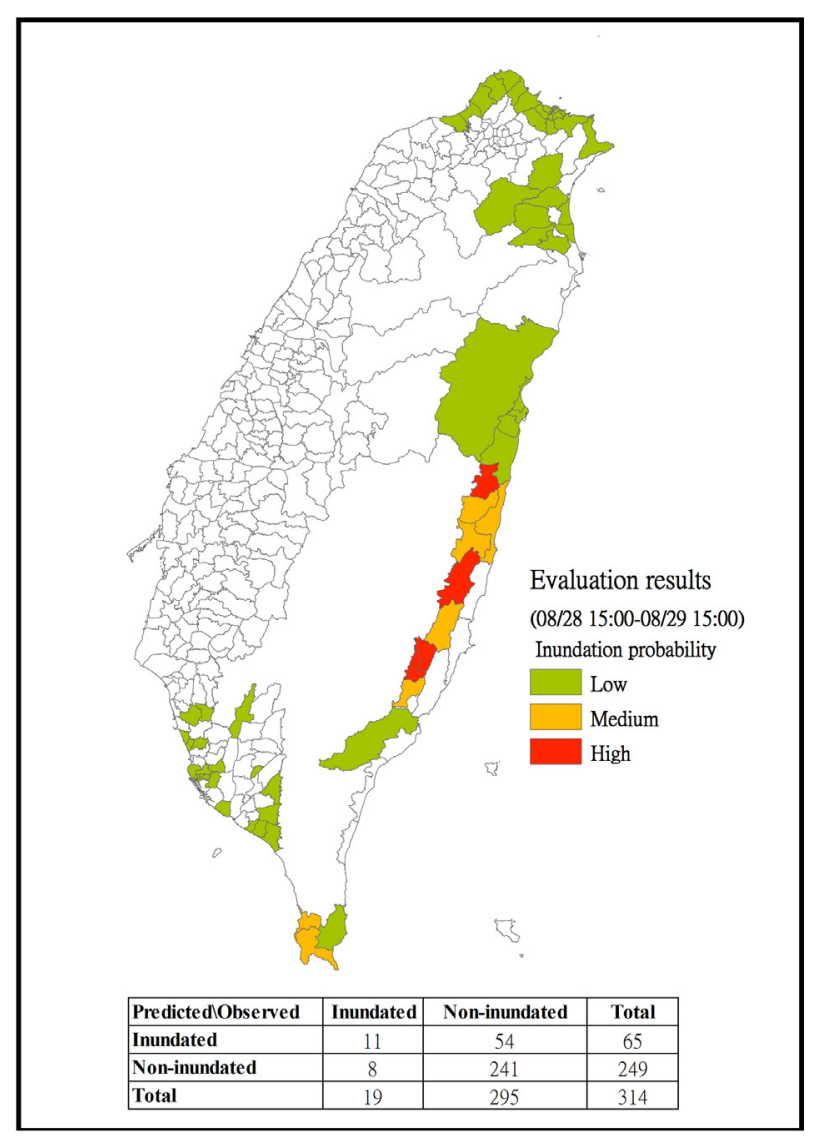

(b)

Fig. 9. Evaluation results of inundation probability for Typhoon Nanmadol based on TYQPFE precipitation by (a) CSC method and (b) PEM method.

ate the precision of the inundation estimation. The observed 24-h precipitations from Typhoon Megi and Typhoon Nanmadol were collected. The maximum 1 - and 2 -h precipitation depths were used to evaluate the inundation probability. The difference between considering only 1 -h precipitation depth and considering both 1 and 2 -h precipitation depths was also tested. The CSC method introduced in Section 2.2.1 was used to evaluate the inundation probability. As shown in Figs. 6 and 7, inundation evaluation using the observed precipitation can well predict the extent of inundation, regardless of whether only 1 -h precipitation depth or both 1 - and 2-h precipitation depths are considered. The results indicate that considering both the 1 - and 2 -h precipitation depths are more conservative, which provides a forecast of more townships suffering from inundation than when only 1 -h precipitation depth is considered.

We further used four indices (Eqs. (3)-(6)) to quantify the difference between the two sampling methods of choosing the precipitation data for analysis. The verification results are shown in Tables 1 and 2. As shown in Table 1 for Typhoon Megi, the POD values for both methods are 1 . It shows that this evaluation system is capable of forecasting inundations. Notably, because both 1 - and 2-h precipitation depths were included for analysis, more townships were forecast to be inundated, which leaded to more false alarms. This caused the TS to be lower and the BS and FAR values to be larger than that when considering only 1 -h precipitation depth. It seems that when both 1 - and 2 -h precipitation depths are included for analysis, although the false alarm rate is apparently large, it results in a more conservative prediction to include all the possible inundation cases in practice.
The evaluation results of Typhoon Nanmadol event shown in Table 2 also validate the aforementioned discussion. In this event, though more townships are forecast to be inundated when both 1and 2-h precipitation depths are considered, there are more accurately forecast hits. As shown in Table 2, the POD is 0.789 , which is more favorable than the 0.579 obtained when only 1 -h precipitation depth is considered by the system. Except the BS index, all the other indexes show that the system considering both 1- and 2-h precipitation depths provides a more accurate inundation forecast. Therefore, overall consideration proves that the POD yields more favorable results when both 1- and 2-h precipitation depths are considered in evaluating inundations. Other indices may be more or less favorable depending on the characteristics of the storm event.

From the decision maker's perspective, a more conservative system is preferable in order to avoid that an actual inundation occurs, but the system does not disseminate warning messages. Consequently, the sampling method of adopting both 1- and 2-h precipitation depths is used in the system in the following discussion using ensemble quantitative precipitations.

\subsection{Inundation evaluation using TYQPFE precipitation}

From the results discussed in the previous section, the proposed inundation model has shown its capability for evaluating storm sewer flooding using the observed precipitation data. To fulfill the objective of the system for inundation forecast, forecast precipitations generated from TYQPFE were used. Verification results from 24-h accumulated precipitation for Typhoon Megi and Ty- 
phoon Nanmadol are shown in Tables 3 and 4 based on the indices defined in Section 4.1. The TS at the threshold value of $130 \mathrm{~mm}$ are 0.78 and 0.61 , respectively. It shows that the precipitation forecast could be a valuable reference in practice although the Bias score indicate that the precipitation forecasts were overestimated in these two typhoons.

Results for inundation forecast using TYQPFE are shown in Figs. 8 and 9. As shown in these figures, extra errors were introduced into the inundation evaluation system in comparison with the forecast inundation shown in Figs. 6 and 7; nevertheless, the results were considered acceptable in practice. As shown in Fig. 8 for Typhoon Megi, both methods predicted the inundation mainly occurring in Yilan County (the north-east corner), which was consistent with the actual inundation area shown in Fig. 5a. Although a long strip region of north-south direction was forecast inundation, flooding did not actually occur in this area. The reason for this false alarm may be due to only few residents in this area, so there is no inundation record. A similar false alarm also occurred in Typhoon Nanmadol, which can be seen in Fig. 9. To quantify the pros and cons of the two inundation-evaluation methods, verification indices shown in Tables 1 and 2 are detailed investigated. The POD index for both methods reaches 0.857 in Typhoon Megi (Table 1), which demonstrates that the two methods are capable of providing disaster prevention information to decision makers in advance. Nevertheless, because of higher false alarms shown in the PEM method, the other three indices show that the analysis results of the PEM method are worse than those of the CSC method. As shown in Table 2, the difference of the indices' values between the two methods is more obvious in Typhoon Nanmadol, and all indices indicate that the CSC method is superior to the PEM method. The main reason is that the PEM method including probabilistic evaluation results from all the members, which leads to less false alarms than that in the CSC method.

Basically, the aforementioned verifications have demonstrated that the proposed system is capable of providing early forecasts on potential inundation areas. An integrated platform will be developed in the near future to disseminate inundation warning messages to authorities for disaster mitigation measures.

\section{Conclusions}

This study combines the TYQPFE and storm sewer design capacity to establish an inundation evaluation system for flood early warning in the metropolitan areas of Taiwan. We propose two methods to evaluate inundation probabilities: the CSC method and the PEM method. To realize the effect of using 1- or 2-h precipitation depths in inundation evaluations, we use Typhoon Megi and Typhoon Nanmadol as test cases. Four verification indices are used with the CSC method to evaluate the probability of a metropolitan area being inundated during typhoons. The results indicate that considering both 1 - and 2-h precipitation depths yields more favorable forecasting on inundation. In addition, when using the TYQPFE forecast precipitation, the CSC method offers more accurate results than the PEM method. It is all because that the PEM method employs all the members' results in probabilistic evaluations, which predicts more townships to be inundated than employing the CSC method. On the basis of the inundation records from two typhoon events, it is concluded that the proposed inundation evaluation system combining the TYQPFE with sewer design capacity is capable of identifying inundation areas and offers valuable information for early flood warning during typhoon. The inundation evaluation system has been tested online during typhoon period in 2012 and will be improved continuously.

\section{Acknowledgments}

The authors would like to thank the Central Weather Bureau (CWB), the National Science and Technology Center for Disaster Reduction (NCDR), National Taiwan University (NTU), National Taiwan Normal University (NTNU), National Central University (NCU) and Chinese Culture University (CCU) for participating the ensemble forecasting. The computation resources provided for this study by the National Center for High-performance Computing ( $\mathrm{NCHC}$ ) are hereby gratefully acknowledged.

\section{References}

Bartholmes, J.C., Thielen, J., Ramos, M.H., Gentilini, S., 2009. The European flood alert system EFAS - Part 2: statistical skill assessment of probabilistic and deterministic operational forecasts. Hydrol. Earth Syst. Sci. 13, 141-153.

Burlando, P., Rosso, R., Cadavid, L.G., Salas, J.D., 1993. Forecasting of short-term rainfall using ARMA models. J. Hydrol. 144, 193-211.

Chen, A.S., Hsu, M.H., Chen, T.S., Chang, T.J., 2005. An integrated inundation model for highly developed urban areas. Water Sci. Technol. 51 (2), 221-229.

Chen, A.S., Hsu, M.H., Teng, W.H., Huang, C.J., Yeh, S.H., Lien, W.Y., 2006 Establishing the database of inundation potential in Taiwan. Nat. Hazards 37, 107-132.

Chien, F.C., Hong, J.S., Chang, W.J., Jou, B.J.D., Lin, P.L., Lin, T.E., Liu, S.P., Miou, H.J., Chen, C.Y., 2006. A sensitivity study of the WRF model. Part II: verification of quantitative precipitation forecasts. Atmos. Sci. 34 (3), 261-276 (in Chinese with an English abstract).

Chou, K.H., Wu, C.C., Yen, T.H., 2001. The evolution of Typhoon Zeb in a nonhydrostatic mesoscale model. Atmos. Sci. 29, 291-314 (in Chinese with an English abstract).

Colle, B.A., Mass, C.F., Westrick, K.J., 2000. MM5 precipitation verification over the Pacific northwest during the 1997-1999 cool seasons. Weather Forecast. 15 730-744.

Cunge, J.A., Holly, F.M., Verwey, A., 1980. Practical Aspects of Computational River Hydraulics. Pitman Publishing Ltd., London.

Docine, L., Andrieu, H., Creutin, J.D., 1999. Evaluation of a simplified dynamical rainfall forecasting model from rain events simulated using a meteorological model. Phys. Chem. Earth Part B 24 (8), 883-887.

Dudhia, J., 1993. A nonhydrostatic version of the Penn state/NCAR mesoscale model: validation tests and simulation of an Atlantic cyclone and cold front. Mon. Weather Rev. 121, 1493-1513.

Emanuel, K.A., 2005. Increasing destructiveness of tropical cyclones over the past 30 years. Nature $436,686-688$.

Georgakakos, K.P., 2006. Analytical results for operational flash flood guidance. J. Hydrol. 317 (1-2), 81-103.

Grimit, E.P., Mass, C.F., 2002. Initial results of a mesoscale short-range ensemble forecasting system over the Pacific northwest. Weather Forecast. 17, 192-205.

Grell, G.A., Dudhia, J., Stauffer, D.R., 1994. A Description of the Fifth-generation Penn State/NCAR Mesoscale Model (MM5). NCAR Technical Note, NCAR/TN-398+STR, $121 \mathrm{pp}$.

Guo, W.D., Ho, H.Y., Feng, W.S., 2011. A Rapid Evaluating System for Urban Inundation Assessment. EGU General Assembly 2011, Vienna, Austria.

Jankov, I., Gallus, W.A., Segal, M., Shaw, B., Koch, S.E., 2005. The impact of different WRF model physical parameterizations and their interaction on warm season MCS rainfall. Weather Forecast. 20, 1048-1060.

Klatt, P., Schultz, G.A., 1983. Flood forecasting on the basis of radar rainfall measurement and rainfall forecasting. Proceedings of Hamburg Symposium, IAHS Publ. 145, 307-315.

Lee, C.S., Luo, Y.Z., Chang, L.Y., 2007. A study on the heavy rainfall due to the interactions of Typhoon Lynn (1987) and the northeasterly monsoon. Atmos. Sci. 35, 13-33 (in Chinese with an English abstract).

Liu, S.C., Fu, C., Shiu, C.-J., Chen, J.-P., Wu, F., 2009. Temperature dependence of global precipitation extremes. Geophys. Res. Lett. 36, L17702.

Luk, K.C., Ball, J.E., Sharma, A., 2001. An application of artificial neural networks for rainfall forecasting. Math. Comput. Model. 33, 683-693.

Norbiato, D., Borga, M., Degli, E.S., Gaume, E., Anquetin, S., 2008. Flash flood warning based on rainfall thresholds and soil moisture conditions: an assessment for gauged and ungauged basins. J. Hydrol. 362, 274-290.

Reed, D.W., 1984. A Review of British Flood Forecasting Practice. Report No. 90, Institute of Hydrology, Wallingford, UK

Skamarock, W.C., Klemp, J.B., Dudhia, J.D., Gill, O., Barker, D.M., Wang, W., Powers, J.G., 2005. A Description of the Advanced Research WRF Version 2. NCAR Tech. Note TN-468_STR, 88pp.

Sperfslage, J.A., Georgakakos, K.P., Carpenter, T.M., Shamir, E., Graham, N.E., Alfaro, R., Soriano, L., 2004. Central America Flash Flood Guidance (CAFFG) User's Guide. HRC Limited Distribution Report No. 21, Hydrologic Research Center, San Diego, CA, p. 82.

Tanguy, J.M., Carriere, J.M., Trionnaire, Y., Schoen, R., 2005. Reorganisation of flood forecasting in France - Reorganisation de l'annonce des crues en France. La Houille Blanche 2, 44-48. 
Thielen, J., Bartholmes, J., Ramos, M.H., Roo, A., 2009. The European flood alert system - Part 1: concept and development. Hydrol. Earth Syst. Sci. 13, 125-140.

Versini, P.A., Gaume, E., Andrieu, H., 2010. Application of a distributed hydrological model to the design of a road inundation warning system for flash flood prone areas. Nat. Hazards Earth Syst. Sci. 10, 805-817.

Yang, M.J., Ching, L., 2005. A modeling study of Typhoon Toraji (2001): physical parameterization sensitivity and topographic effect. Terr. Atmos. Ocean Sci. 16, 177-213.
Yu, P.S., Chen, S.T., Wu, C.C., Lin, S.C., 2004. Comparison of grey and phase-space rainfall forecasting models using fuzzy decision method. Hydrol. Sci. J. 49 (4), $655-672$.

Yu, P.S., Chen, S.T., 2005. Updating real-time flood forecasting using a fuzzy rulebased model. Hydrol. Sci. J. 50 (2), 265-278.

Zevin, S.F., 1986. A Probabilistic Approach to Flash Flood Forecasting. Ph.D. Dissertation, Dept. of Hydrology and Water Resources Administration, Univ. of Arizona, USA. 